Araştırma ve Geliştirme Dergisi UMAGD, (2022) 14(1), 103-114.

International Journal of

Engineering Research and

Development

10.29137/umagd.956063

\author{
Cilt/Volume:14 Sayı/Issue:1 Ocak/January 2022
}

Araştırma Makalesi / Research Article

\title{
Atık Mermerlerin Parke Taşlarında İnce Agrega Olarak Kullanılabilirliğinin İncelenmesi
}

\section{Investigation of Usability of Waste Marble as Fine Aggregate in Paving Stones}

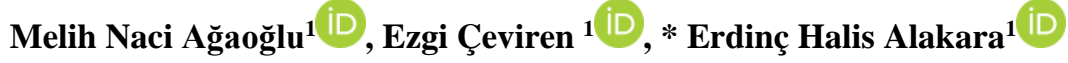 \\ ${ }^{I}$ Tokat Gaziosmanşa Üniversitesi Mühendislik ve Mimarlık Fakültesi İnşaat Mühnedisliği Bölümü, 60000 Tokat, Türkiye
}

Başvuru/Received: 22/06/2021Ｋabul/Accepted: 16/09/2021Ｃ̧evrimiçi Basım/Published Online: 31/01/2022

Son Versiyon/Final Version: 31/01/2022

\begin{abstract}
$\ddot{O} \mathbf{z}$
Bu çalışmada, Tokat ili mermer işleme fabrikalarında oluşan atık mermerlerin beton parke taşlarında ince agrega olarak kullanımının uygunluğu araştırılmıştır. Karışımlarda bağlayıcı olarak CEM I 42.5 R tipi çimento kullanılmıştır. Agrega olarak en büyük tane çapı $8 \mathrm{~mm}$ olan kalker kökenli kırmataş agrega ile en büyük tane çap $14 \mathrm{~mm}$ olan atık mermer agregası kullanılmıştır. Karışımlarda şebeke suyu kullanılmış olup herhangi bir kimyasal katkı malzemesi kullanılmamıştır. Çalışma kapsamında Karayolları Teknik Şartnamesi (2013) beton parke taşları özelliklerine uygun olarak doğal agrega gradasyonu hazırlanmıştır. Bu gradasyon sabit tutularak atık mermerler agrega karışımının ince agrega grubuna kütlece $\% 25, \% 50, \% 75$ ve $\% 100$ oranında ikame edilmiştir. Beş ayrı deneye tabi tutulan beş farklı (\%0 (katkısız), \%25, \%50, \%75 ve \%100) karışım oranına sahip numune gruplarında her bir deney için 3 adet numune olmak üzere toplamda 75 adet $(5 \times 5 \times 3)$ beton parke taşı numunesi hazırlanmıştır. Hazırlanan numunelerin deney sonuçları incelendiğinde, boyut-görünüş, su emme oranı, donma-çözünme direnci ve aşınma direnci bakımından şartname limitlerinin sağlandığı görülmüştür. Yarmada çekme dayanımı özellikleri incelendiğinde ise $\% 25$ ve $\% 50$ oranında ikame edilen mermer agregası ile hazırlanan numunelerin yeterli dayanım gösterdiği; buna karşın $\% 75$ ve $\% 100$ oranında ikame edilen mermer agregası ile hazırlanan numunelerin ise yeterli dayanımı sağlamadığı görülmüştür. Sonuç olarak atık mermerlerin beton parke taşlarında ince agrega olarak \%50 oranına kadar kullanılabilir olduğu tespit edilmiştir.
\end{abstract}

\section{Anahtar Kelimeler}

"Atık mermer, Parke taşı,Geri dönüşüm, Yarmada çekme dayanımı, Aşınma kaybl, Donma-çözünme direnci”"

\begin{abstract}
In this study, the suitability of the use of waste marbles formed in marble processing factories in Tokat province as fine aggregate in concrete paving stones was investigated. CEM I $42.5 \mathrm{R}$ type cement was used as binder in the mixtures. As agen gregates, limestone-based crushed stone aggregate and waste marble aggregate were used. Tap water was used in the mixtures and no chemical additives were used. Within the scope of the study, natural aggregate gradation was prepared in accordance with the specifications of the Highways Technical Specification (2013) concrete paving stones. By keeping this gradation constant, waste marbles were substituted for the fine aggregate group of the aggregate mixture at the rate of $25 \%, 50 \%, 75 \%$ and $100 \%$. In the sample groups with five different mixing ratios, which were subjected to five different tests, a total of $75(5 \times 5 \times 3)$ concrete paving stone samples were prepared, 3 for each test. When the test results of the prepared samples were examined, it was seen that the specification limits were met in terms of size-appearance, water absorption rate, freeze-thaw resistance and abrasion resistance. When the split tensile strength properties are examined, it is seen that the samples prepared with $25 \%$ and $50 \%$ substituted marble aggregate show sufficient strength; On the other hand, it was observed that the samples prepared with 75\% and 100\% substituted marble aggregate did not provide sufficient strength. As a result, it has been determined that waste marbles can be used up to $50 \%$ as fine aggregate in concrete paving stones.
\end{abstract}

Key Words

"Waste marble, Paving stone, Recycling, Splitting tensile strength, Abrasion loss, Freeze-thaw resistance" 


\section{Giriş}

Beton, temel olarak agrega, su, bağlayıcı malzeme ve katkılardan oluşan kompozit bir yapı malzemesidir. Yüksek mukavemet, çevresel koşullara karşı dayanıklılık, diğer inşaat malzemelerine kıyasla daha ekonomik olması gibi özelliklere sahiptir. Tüm bu özelliklerinden dolayı beton, günümüzde en yaygın kullanılan yapı malzemesi olmuştur. Betonu oluşturan bileșenler arasında agrega, toplam beton hacminin yaklaşı $\% 60-\% 75$ ' ini oluşturmaktadır. Bu sebeple agrega, betonun performansını etkileyen en önemli malzemelerden birisi olmaktadır (Behera vd., 2014). Agregalar, inşaat sektöründe hemen her alanda kullanılan yapı malzemeleridir. Beton karışımlarında, yol kaplamalarında, demiryolu inşaatında, drenaj sistemlerinde vs. pek çok kullanım alanı vardır. Agregalar doğal ve yapay olmak üzere farklı şekillerde elde edilebilmektedirler (Baradan vd., 2015).

Son yıllarda sanayileşme ve kentleşme hızındaki büyük artış, betonun yüksek miktarda doğal kaynak tüketmesine neden olmaktadır Her yıl yaklaşık 20 milyar ton hammadde (kaba agrega) kullanılmaktadır. Bu nedenle beton endüstrisi; hammaddenin \%50' sini, toplam enerjinin \%40' ını ve toplam atıkların \%50' sini oluşturduğu için çevre, enerji ve ekonomi alanlarında önemli kayıplara neden olmakta ve büyük miktarlarda doğal kaynak tüketmektedir (Oikonomou, 2005). Böylece, inşaatta kullanılacak betonun; çevresel etki, enerji tüketimi ve $\mathrm{CO}_{2}$ yoğunluğunun en aza indirilmesi ile ilgili çalışmalar inşaat sektörü için oldukça önemli bir hale gelmiştir.(Anitha vd., 2021; Saloni vd., 2021; Binici, 2007; Demir, 2009)

Parke kaplamalar, Romalılardan beri kullanıla gelmiş bir üst yapı tipidir. Parke taş kaplamalar; temiz, dayanıklı ve tekerlek yuvarlanmasına elverişli bir yüzey oluşturması açısından oldukça avantajlı bir kaplama çeşididir. Parke taşlar, ağır taşıt trafiğinin olmadığı yollarda ulaşım ve peyzaj amaçlı olarak kullanımı her geçen gün artan, doğal veya yapay olarak elde edilen zemin kaplama malzemeleridir. (Filiz vd., 2010). Şehir içi yollar, park alanları, meydanlar, endüstriyel sahalar, kaldırımlar ve benzeri birçok yerde çok eskiden beri doğal taşlardan veya betondan imal edilen parkeler kullanılmaktadır. Ancak son yıllarda doğal taşların yerini prefabrik üretim olan beton parkeler almaktadır. Bunun nedeni olarak; istenilen şekillerde ve renklerde üretilmesi, her mevsimde uygulanabilmesi, döşeme ve sökme işlerinin kolay olması, çatlama ve kırılma olayının daha az olması, istenilen dayanımda üretilebilmesi gibi özelliklerinin olması söylenebilir (Yüksel vd., 2007; Kaya \& Karakurt 2016).

Mermer, hemen her yerde kullanım alanı bulan ve dünyada oldukça fazla miktarda bulunan madenlerden biridir. Dünyadaki kaliteli ve en zengin mermer yataklarının büyük bölümünün Akdeniz ülkelerinde yer aldığı bilinmektedir. Türkiye, dünyada mermer üretiminde ve ihracatında ilk sıralarda yer alan ülkeler arasındadır. Mermerin ocaktan çıkarılması ve tesislerde işlenmesi sırasında oldukça büyük miktarlarda atıklar oluşmaktadır. Bu atıklar büyük parçalar şeklinde veya toz halinde olmaktadır. Mermer işleme tesislerinin yoğun olarak bulunduğu bölgelerde bu atıklar çevreyi olumsuz etkilemektedir. Ayrıca bu atıkların sebep olduğu tozlar yakın çevresindeki bitki örtüsüne de ciddi zararlar vermektedir (Öztürk, 2018; Filiz vd., 2010).

Son yıllarda atık malzemelerin betonda kullanımıyla ilgili birçok çalışma yapılmıştır (Miraldo vd., 2021; Kim\& Lee 2011; Patra \&Mukharjee, 2017; Coppola vd., 2016). Beton parke taşlarında atık malzeme kullanımıyla ilgili çalışmalardan bazıları ise aşağıda verilmiştir.

Kırılmış tuğla atıklarının parke taşlarında kullanımının araştırıldığı çalışmada; tuğla kırıkları doğal agrega yerine $\% 100, \% 65, \% 60$, $\% 50, \% 32.5$ ve $\% 25$ oranlarında kullanılmıştır. Tuğla agregasının yüzdesi arttıkça betonun yoğunluğu azalmış, su emme oranı yükselmiş, basınç ve yarmada çekme mukavemeti değerleri azalmıştır. Tüm karışımların su emme değeri maksimum \%6 sınırını aşmıştır. Donma-çözülme testi sonrası kütle kaybı ise tüm karışımlar için maksimum $1 \mathrm{~kg} / \mathrm{m}^{2}$ değerinin altında kalmış ve en iyi hava koşullarına dayanıklılık sınıfının gereksinimlerini karşılanmıştır. Tuğla agregasının yüzdesi arttıkça numunelerin aşınma direnci azalmıştır. Ancak tüm karışımlar standardın belirlemiş olduğu minimum gereksinimleri karşılamıştır. Çalışma sonucunda standardın gerekliliklerini karşılayan beton parke taşlarını hazırlamak için agrega olarak \%32.5 oranına kadar geri dönüştürülmüş tuğla agregası kullanmanın mümkün olduğu görülmüştür (Jankovic vd., 2012).

Hindistan'da yapılan bir çalışmada, doğal agrega ile farklı yüzdelerde atık mermer agregası ikame edilmiştir. Su emme, basıç dayanımı ve yarmada çekme dayanımı deneyleri yapıldığında elde edilen sonuçlara göre; geleneksel agreganın, \%70 orana kadar mermer atığı agregası ile değiştirilmesinin optimum sonuçlar için yeterli olduğu görülmüştür. Atık malzeme kullanımı ile maliyetin düştüğü ve inşaat atıklarının bertaraf edilmesi sorunun çözülmesi ile çevrenin korunmasına yardımcı olunduğu sonucuna varılmıştır (Khandve \& Rathi, 2015).

Geri dönüştürülmüş atık lastiklerin beton parke taş üretiminde, kum yerine hacimce $\% 0, \% 10, \% 20$ ve $\% 30$ oranlarında kullanıldığı çalışmada; yoğunluk, basınç dayanımı, eğilme dayanımı ve kayma direnci gibi fiziksel ve mekanik özellikleri incelenmiştir. \%10 oranında atık lastik eklenmesi ile basınç dayanımı katkısız numunelerine kıyasla artmıştır. Ancak \%20 ve \%30 oranında atık lastik kullanılması durumunda numunelerde büyük gözeneklilik gözlenmiş ve bu durum önemli derecede dayanım kaybına neden olmuştur. Ayrıca, atık lastik kullanımı betonun gevrek davranışını azaltarak daha sünek bir yapının elde edilmesini sağlamıştır (Ling, 2012).

Silva vd. (2013) farklı oranlarda ince agrega içeren taze ve sertleşmiş betonun mekanik özelliklerini incelemiştir. Karışımlarda atık mermerler $\% 0, \% 20, \% 50$ ve $\% 100$ oranlarında agrega olarak kullanılmıştır. $\% 60$ ' a varan ikame oranlarında betonun mekanik 
özelliklerinde iyileşmeler gözlemlenmiştir. Sonuç olarak, mermer ocaklarından elde edilen atıkların beton üretiminde ve özellikle $\% 60$ 'a varan oranlarda kullanılmasının yeterli olduğu tespit edilmiştir.

Durmuş \& Şimşek (2008) yapmış oldukları çalışmada çimentoya \%10, \%20, \%30 ve \%40 oranında uçucu kül (UK) ikame ederek parke taşı hazırlamışlardır. Üretilen parke taşlarına standart ve tuzlu su kürü uygulanmıştır. Beton parke taşlarının yarmada çekme, su emme ve aşınma özellikleri incelenmiştir. Sonuç olarak tuzlu su küründe, erken yaşlarda, yarmada çekme dayanımını arttıırken, ileriki yaslarda düşürmüștür. Ayrıca, beton parke taşında UK ikame oranının artıkça aşınma kaybı değerinin arttığı ve su emme oranının ise azaldığı tespit edilmiştir.

Mermer tozunun parke taşlar üzerindeki etkisinin incelendiği çalışmada, iki farklı çimento tipi ve iki farklı su/çimento oranı kullanılmıştır. Elde edilen sonuçlar incelendiğinde, mermer tozu kullanımı ile betonların fiziksel ve mekanik özelliklerinin katkısız numunesine göre yükseltilebildiği (basınç dayanımını $\% 32.3$, yarmada çekme dayanımını $\% 13.5$ ve elastisite modülü değerlerini $\% 15.2$ arttırılabilmekte, su emme oranını \%25.8, aşınma kaybını \%8.4 ve donma çözülme sonrası mukavemet kaybını \%87.7 azaltabilmektedir) görülmüştür (Filiz vd., 2010).

Atık çay külünün beton parke taşlarına olan etkisinin incelendiği çalışmada, atık çay külü çimentoya \%10, \%20, \%30, \%40 ve \%60 oranında ikame edilmiş̧ir. İşlenebilirlik, yoğunluk, basınç ve eğilme dayanımı, su emme, asit saldırılarına karşı direnci ve çeşitli mikro yapı testlerinin uygulandığı çalışmada fiziksel ve mekanik özellikler incelenmiştir. Atık çay külünün gözenekli olmasından dolayı, parke taşlarının boşluğu artmış ve atık çay külü ikamesi parke taşlarının kalitesini düşürmüştür. Ancak \%20 ve \%40 atık çay külü içeren parke taşlarının sırasıyla C sınıfı (yaya alanları) ve D sınıfı (bahçe alanları) için Endonezya Ulusal Standardı tarafından belirlenen minimum koşulları sağladığı tespit edilmiştir. Bu nedenle, atık çay külünün çimentoya ikame edilmesinin sürdürülebilirlik ve düşük maliyet açısından önemli katkılar sağlayacağı düşünülmüştür (Djamaluddin vd., 2020).

$\mathrm{Bu}$ çalışmada, Tokat ili mermer işleme tesislerinde ortaya çıkan atık mermer parçalarının beton parke taşlarında ince agrega olarak kullanılabilirliği incelenmiştir. Deneysel çalışma kapsamında, öncelikle atık mermer parçaları laboratuvar tipi konkasörde kırılarak ince agrega boyutuna getirilmiştir. Sonrasında, atık mermerler, agrega karışımının ince agrega grubuna kütlece $\% 25, \% 50, \% 75$ ve $\% 100$ oranlarında ikame edilmiştir. Katkısız numuneleri ile farklı oranlarda atık mermer agregası içeren beton parke taşı numunelerine boyut-görünüş analizi, aşınma direnci tayini, yarmada çekme deneyi, su emme deneyi ve donma-çözünme deneyleri uygulanarak sonuçlar birbiriyle kıyaslanmıştır. Elde edilen sonuçlara bakılarak, üretilen numunelerin dahil olduğu sınıflar Tablo 1' de gösterilen Karayolu Teknik Şartnamesi’ ne göre belirlenmiştir.

Tablo 1. Prefabrik beton parke numunelerine yapılacak deneyler ve uygunluk kriterleri (Karayolu Teknik Şartnamesi 2013)

\begin{tabular}{|c|c|}
\hline Deney & Uygunluk kriteri \\
\hline Fiziksel Görünüş & $\begin{array}{l}\text { Parke taşlarının yüzeyinde çatlak, kırık, çukur, döküntü, pullanma } \\
\text { veya soyulma bulunmamalı ve yüzleri düzgün ve köşeleri muntazam } \\
\text { olmalı, simetri ve biçim bozuklukları bulunmamalıdır. }\end{array}$ \\
\hline Malzeme Özellikleri & $\begin{array}{l}\text { Üretimlerde kullanılacak agrega, çimento, su, kimyasal katkılar ve } \\
\text { boya katkıları Kısım } 316.01 .02 \text { 'de belirtilen kriterlere uygun } \\
\text { olacaktır. }\end{array}$ \\
\hline $\begin{array}{l}\text { Boyutlar Yönünden } \\
\text { Uygunluk }\end{array}$ & Kısım 316.01.03'e uygun olmalıdır. \\
\hline Su Emme Oranı & $\begin{array}{l}\text { 1.Sinıf parkelerde performans ölçümü gerekmez. } \\
\text { 2.Sınıf parkelerde kütlece ortalama olarak } \quad \% 6 \text { 'dan } \\
\text { olmayacaktır. }\end{array}$ \\
\hline Aşınma Dayanımı & $\begin{array}{l}\text { 1.Sınıf parkelerde performans ölçümü gerekmez. } \\
\text { 2. ve 3.Sınıf parkelerde Geniş, Diskli Aşınma deney metodu } \\
\text { kullanılarak ölçülen değer } 23 \mathrm{~mm} \text { ' den fazla olmayacaktır, alternatif } \\
\begin{array}{l}\text { olarak Böhme deney } \\
\text { sonuçlarından hiçbirisi }\end{array} \\
\begin{array}{l}\text { solodu } \\
\text { olmayacaktır. }\end{array}\end{array}$ \\
\hline Mukavemet & $\begin{array}{l}\text { Mukavemet tayini; TS } 2824 \text { EN } 1338 \text { standardına göre Yarmada- } \\
\text { çekme deneyi yapılarak belirlenecek olup, Kısım 316.01.06.01'de } \\
\text { belirtilen kriterlere uygun olacaktır. }\end{array}$ \\
\hline $\begin{array}{l}\text { Donma ve Çözülme } \\
\text { Dayanımı }\end{array}$ & $\begin{array}{l}\text { 1.Sınıf parkelerde performans ölçümü gerekmez. } \\
\text { 3.Sınıf parkelerde donma çözülme deneyinden sonra metrekaredeki } \\
\text { kilogram kütle kaybı ortalama olarak \%1,0'dan büyük olmamalıdır. } \\
\text { Tek numune sonuçlarından hiçbirisi \%1,5'ten büyük olmamalıdır. }\end{array}$ \\
\hline
\end{tabular}




\section{Deneysel Program}

\subsection{Materyal}

Deneyler kapsamında TS EN 197-1 standardına uygun normal Portland çimentosu (CEM I 42.5 R) kullanılmıştır. Çimentoya ait kimyasal özellikler Tablo 2' de verilmiştir. Çalışmada agrega olarak; kalker kökenli "0-4 mm" ve "4-8 mm" boyutuna sahip doğal agrega (D) ile atık mermer parçalarından elde edilen " $0-4 \mathrm{~mm}$ " boyutuna sahip mermer agregaları (M) kullanılmıştır. Agregalara ait granülometri eğrileri Şekil 1'de gösterilmiştir. Doğal agregalar, Tokat ilinde beton parke taşlarının imalatında, hali hazırda kullanılmakta olan agregalardan elde edilmiştir. Atık mermer agregaları ise Tokat ili mermer işleme tesislerinde ortaya çıkan ve Şekil 2'de görüldüğ̈̈ gibi büyük bir çevre kirliliğine sebep olan atık mermer sahasından alınan parçaların, laboratuvar tipi çeneli kırıcı ile öğütülmesinden elde edilmiştir. Katkılı numuneler için hazırlanan karışımlarda atık mermer agregaları agrega karışımının ince agrega grubuna kütlece $\% 25, \% 50, \% 75$ ve $\% 100$ oranlarında ikame edilerek kullanılmıştır. Kaba ve ince agrega için özgül ağılık ve su emme oranı değerleri TS 2824 EN 1338' e uygun olarak yapılmıştır. Agregalara ait fiziksel özellikler Tablo 3' te gösterilmiştir. Tablo 4'te ise beton parke taşlarının sağlaması gereken şartname limit değerleri gösterilmiştir.

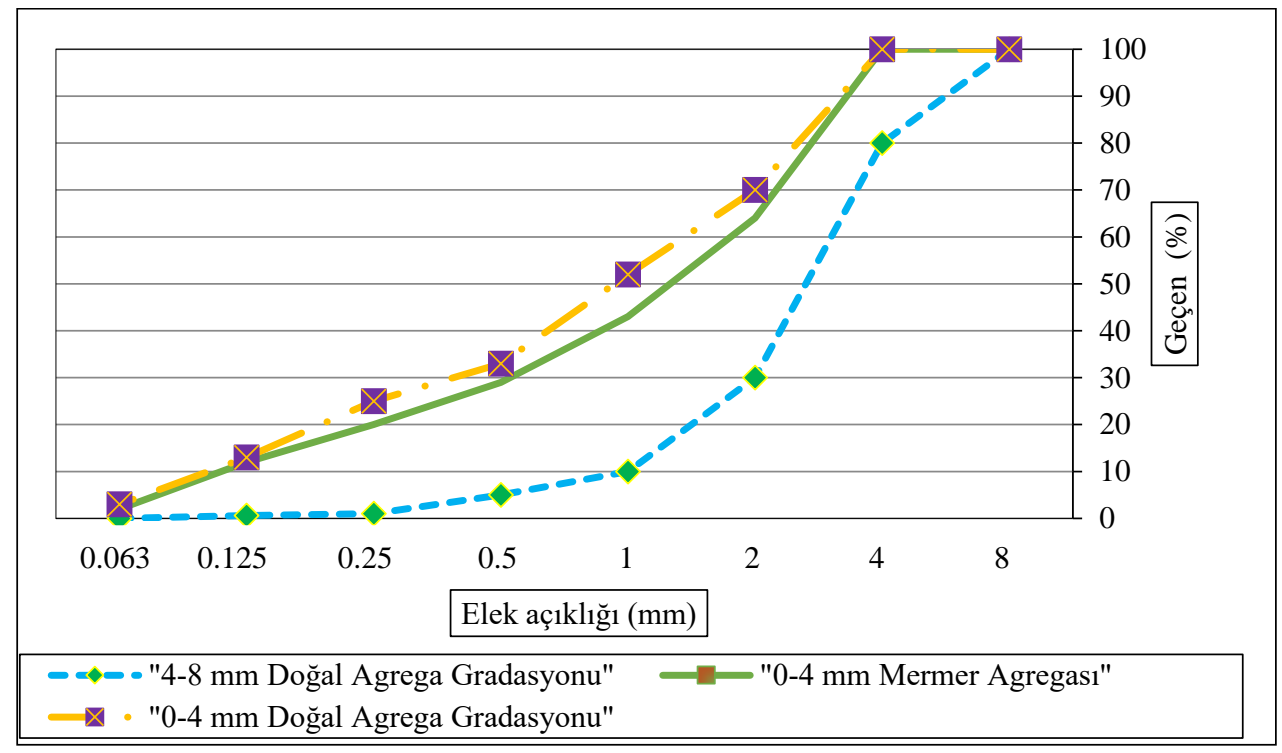

Şekil 1. Agregalara ait granülometri eğrileri

Tablo 2. Çimentoya ait kimyasal özellikler

\begin{tabular}{cc}
\hline Oksit & Çimento (\%) \\
\hline $\mathrm{SiO}_{2}$ & 18.87 \\
$\mathrm{CaO}$ & 62.78 \\
$\mathrm{Na}_{2} \mathrm{O}$ & 0.4 \\
$\mathrm{~K}_{2} \mathrm{O}$ & 0.9 \\
$\mathrm{Al}_{2} \mathrm{O}_{3}$ & 5.62 \\
$\mathrm{SO}_{3}$ & 2.82 \\
$\mathrm{MgO}$ & 2.63 \\
$\mathrm{Fe}_{2} \mathrm{O}_{3}$ & 2.54 \\
$\mathrm{MnO}$ & - \\
Diğerleri & 3.44 \\
\hline
\end{tabular}




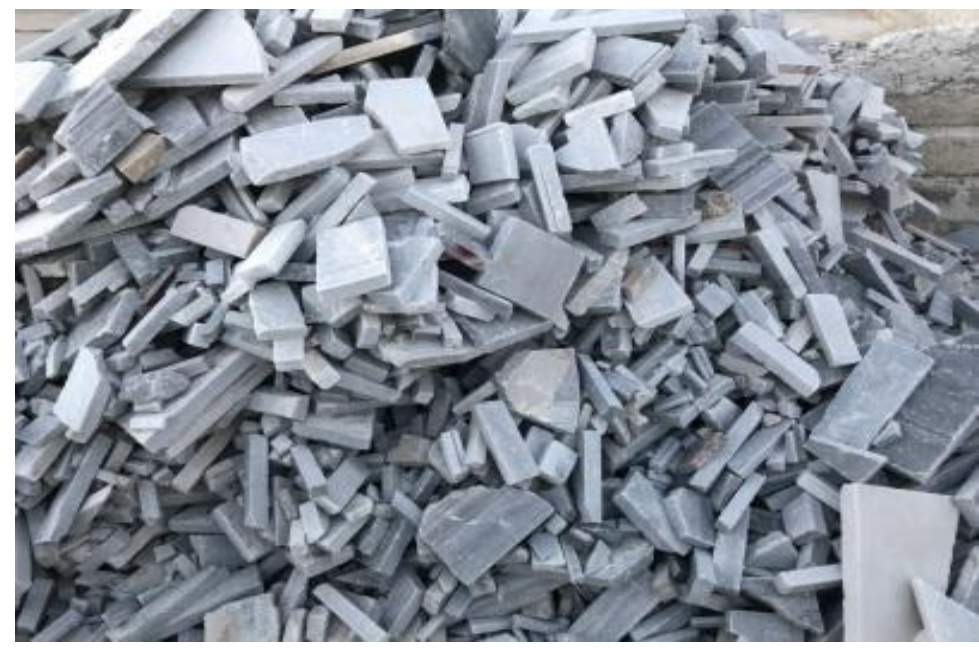

Şekil 2. Atık mermer sahası

Tablo 3. Doğal ve mermer agregalarının fiziksel özellikleri

\begin{tabular}{|c|c|c|c|c|c|}
\hline \multirow[t]{2}{*}{ Agrega Grubu } & \multicolumn{2}{|c|}{ Su Emme (\%) } & \multicolumn{2}{|c|}{ Özgül Ağırlık (gr/cm³) } & \multirow{2}{*}{$\begin{array}{l}\text { Şartname Limiti } \\
\text { (TS 2824 EN 1338) }\end{array}$} \\
\hline & Doğal & Mermer & Doğal & Mermer & \\
\hline $\begin{array}{l}\text { Kaba Agrega } \\
(4-8 \mathrm{~mm})\end{array}$ & 0.44 & - & 2.71 & - & $\begin{array}{l}\text { Su emme max. } \% 2 \\
\text { Özgül ağırlık min. } 2.60 \mathrm{gr} / \mathrm{cm}^{3}\end{array}$ \\
\hline $\begin{array}{l}\text { İnce Agrega } \\
(0-4 \mathrm{~mm})\end{array}$ & 0.66 & 1.30 & 2.68 & 2.63 & $\begin{array}{c}\text { Su emme max. } \% 2 \\
\text { Özgül ağırlık min. } 2.50 \mathrm{gr} / \mathrm{cm}^{3}\end{array}$ \\
\hline
\end{tabular}

Tablo 4. TS 2824 EN 1338 beton parke taşına ait dayanım özellikleri

\begin{tabular}{|c|c|}
\hline Gereklilikler & $\begin{array}{c}\text { SSartname Limiti } \\
\text { (TS 2824 EN 1338) }\end{array}$ \\
\hline Basınç Dayanımı (MPa) & - \\
\hline Çekme Dayanımı (MPa) & $\begin{array}{c}\text { Ortalama } \geq 3,6 \mathrm{MPa} \\
\text { Tek sonuç }>2,9 \mathrm{MPa} \\
\text { Min. kırıllma yükü } 250 \mathrm{~N} / \mathrm{mm}\end{array}$ \\
\hline Su Emme (\%) & $\begin{array}{c}\text { A sinıfi için yok } \\
\text { B sinıfı }(2 . \sin ı) \text { için } \leq 6\end{array}$ \\
\hline Aşıımma Dayanımı & $\begin{array}{c}\text { F sınıfi (1.sınıf) için yok } \\
\text { H sınıfı (3.sınıf) için } \leq 20 \mathrm{~cm}^{3} / 50 \mathrm{~cm}^{2} \\
\text { I sınıfı (4.sınıf) için } \leq 18 \mathrm{~cm}^{3} / 50 \mathrm{~cm}^{2}\end{array}$ \\
\hline
\end{tabular}

\subsection{Metot}

Çalışma kapsamında, beton parke taşları vibrasyonlu ve metal kalıplı parke makinesinde TS 2824 EN 1338'de belirtilen koşullara uygun olarak üretilmiştir. Ayrıca beton karışım hesabında TS 802 dikkate alınmıştır (TS 2824 EN 1338, 2009; TS 802, 2016). Yapılan deneylerde, biri katkısız grup olmak üzere toplamda 5 farklı agrega karışım grubu kullanılmıştır. Tüm karışımlarda su/çimento oranı sabit tutulup bu değer 0.66 olarak alınmıştır. Numuneler üretilirken beton karıştırma işlemi elle yapıldığından ve üretimde kimyasal katkı malzemesi kullanılmadığından su/çimento oranı yüksek tutulmuştur. Karışım gruplarına ait miktarlar Tablo 5' te gösterilmiştir. Beton parke taşlarına; TS 2824 EN 1338' e uygun olarak boyut-görünüş analizi, yarmada çekme deneyi, su emme deneyi, donmaçözülme deneyi ve aşınma direnci deneyi olmak üzere 5 farklı deney yapılmıştır. Bu deneylerin her biri için 3 adet olmak üzere her bir agrega karışım grubu için 15 adet $(3 \times 5)$ ve toplam 5 farklı karışım grubu için 75 adet $(3 \times 5 \times 5)$ numune üretilmiştir. Üretilen numuneler 28 gün kür havuzunda bekletilmiştir. 28 günlük kür sonrası numunelere ait fiziksel ve mekanik özellikler deneyler yardımıyla belirlenmiştir. Şekil 3 ve Şekil 4'te beton parke taşının üretimi gösterilmiştir. 
Tablo 5. $1 \mathrm{~m}^{3}$ parke betonu için karıșım oranları

\begin{tabular}{lcccccc}
\hline Grup Adı & Kaba Agrega (kg) & \multicolumn{2}{c}{ İnce Agrega (kg) } & Çimento (kg) & Su (kg) & $\begin{array}{c}\text { Su/Çimento } \\
\text { Oranı }\end{array}$ \\
\cline { 2 - 4 } & Doğal & Doğal & Mermer & & & \\
\hline D & & 1310 & 0 & & \\
D75M25 & & 983 & 327 & & \multirow{2}{*}{288} & 0.66 \\
D50M50 & 615 & 655 & 655 & & \\
D25M75 & & 327 & 983 & & \\
M & & 0 & 1310 & & \\
\hline
\end{tabular}

Karışım içerikleri şu şekilde oluşturulmuştur:

- D: Kaba ve ince agregaların tamamı doğal agregalardan alınmıştır.

- D75M25: Kaba agreganın tamamı doğal agrega, ince agreganın \%75' i doğal agregadan, \%25' i ise mermer agregasından alınmıştır.

- D50M50: Kaba agreganın tamamı doğal agrega, ince agreganın \%50'si doğal - \%50'si de mermer agregasından alınmıştır.

- D25M75: Kaba agreganın tamamı doğal agrega, ince agreganın \%25'i doğal - \%75'i de mermer agregasından alınmıştır.

- M: Kaba agreganın tamamı doğal agrega, ince agreganın tamamı mermer agregasından alınmıştır.

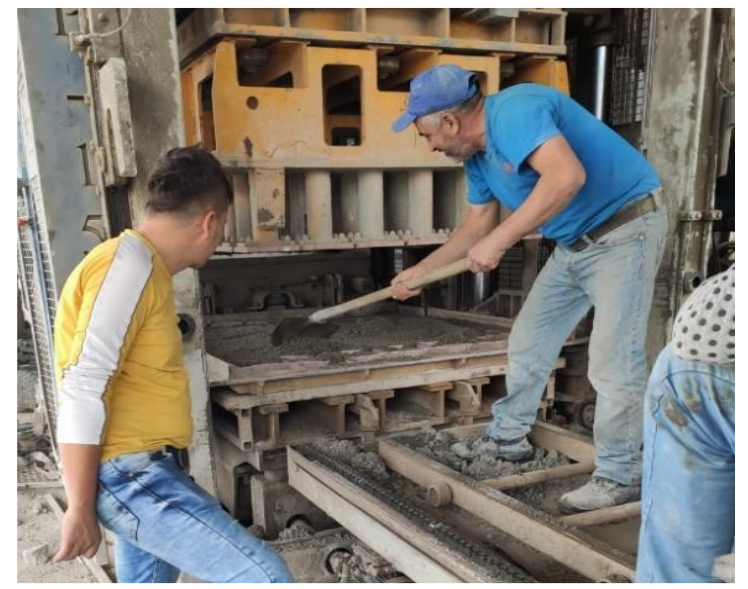

Şekil 3. Beton parke makinasına betonun yerleştirilmesi

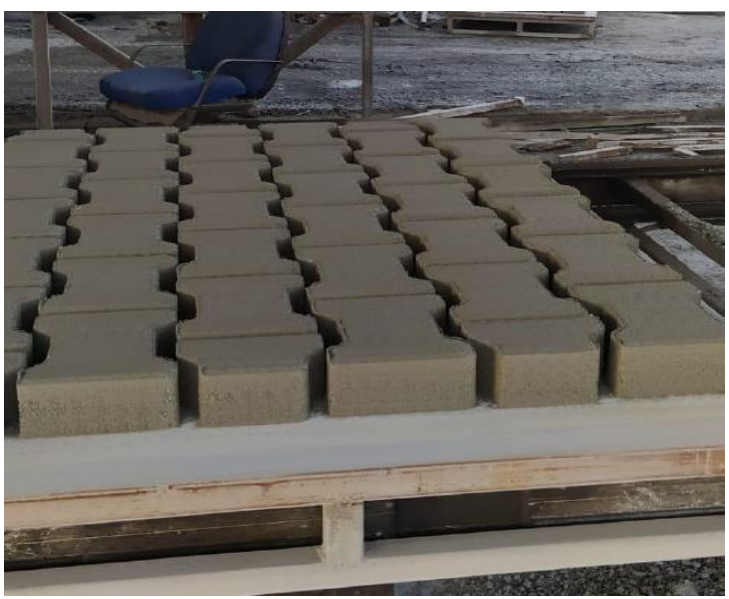

Şekil 4. Beton parke taşların makineden çıkmış hali

\section{Deneysel Bulgular}

\subsection{Beton parke taşlarının boyut ve görünüş analizi sonuçları}

İnce agrega olarak \%25, \%50, \% 75 ve \%100 oranlarında mermer atığı içeren beton parke numunelerine yapılan gözle muayene sonucu; blokların yüzeylerinde kırık, çatlak, pullanma, döküntü, soyulma veya çukurlaşma olmadığı ve yüzeylerinin düzgün, köşelerinin muntazam olduğu, biçimsel bozukluklarının olmadığı görülmüştür. Boyut ölçümü sonucunda ise; atık mermer ince agregasının beton parke bloklarının en, boy, kalınlık ve pah ölçülerinde bir değişikliğe yol açmadığı tespit edilmiş̧ir. Şekil 5 'te numunelerin boyut ölçümü gösterilmiştir. $60 \mathrm{~mm}$ kalınlıktaki numunelerde $5 \mathrm{~mm}$ pah olup, numune uzunluğu $198 \mathrm{~mm}$ ve numune genişliği $163 \mathrm{~mm}$ 'dir. Şekil 6'da üretilen numunelere ait şekil ve boyut uzunlukları gösterilmiştir.

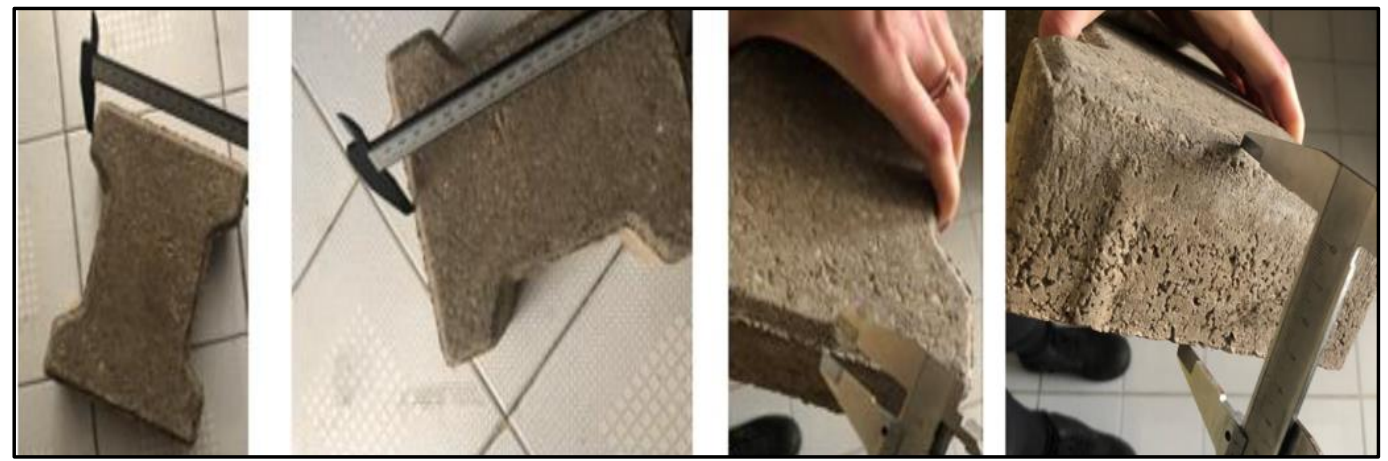

Şekil 5. Numunelerin en, boy, pah ve kalınlık ölçümü 


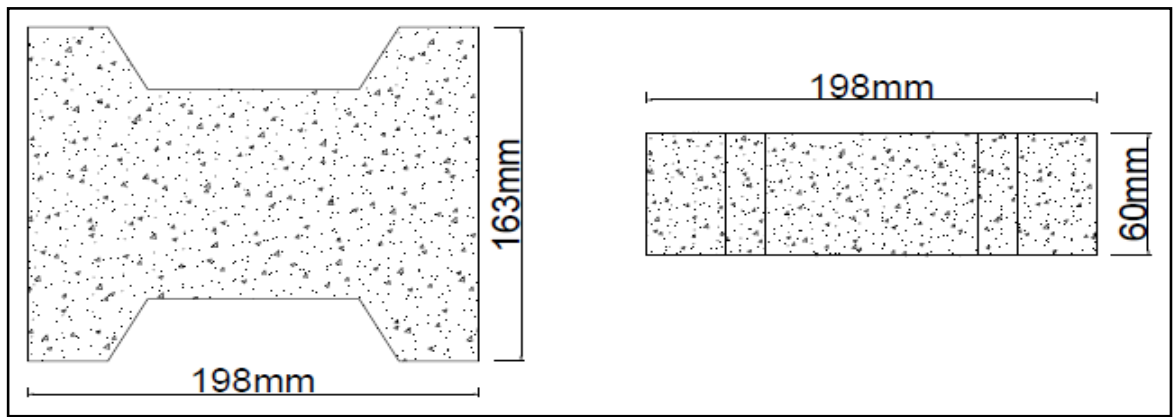

Şekil 6. Beton parke taşına ait şekil ve boyut özellikleri

\subsection{Beton parke taşlarının aşınma direnci deneyi sonuçları}

Şekil 7'de gösterilen aşındırma cihazı ile tüm numunelerin aşınma direnci ölçülmüsştür. Sürtünme ile aşınma kaybını ölçmek için aşındırma tozu olarak alüminyum oksit kullanılır. Geniş aşındırma diski $60 \pm 3$ saniyede 75 dönüş yapacak şekilde çalıştırılır. Aşındırma tozunun akma debisi deney boyunca gözlemlenerek diskin 75 dönüş yapması ile aşındırma tozunun akışı ve diskin dönüsü durdurulur. Kumpas ile ölçüm yapılır. Numunelere uygulanan aşınma direnci deneyi sonuçlarına göre, deneye tabi tutulan tüm numunelerin standartta belirtilen sınır değeri aşmadığı görülmüştür. Beton parke bloklarında aşınmaya maruz kalan 4 mm kalınlıktaki kum tabakasının aşılmayışından dolayı yakın değerler elde edildiği düşünülmektedir. Şekil 8'de numunelere ait aşınma direnci değerleri verilmiştir.

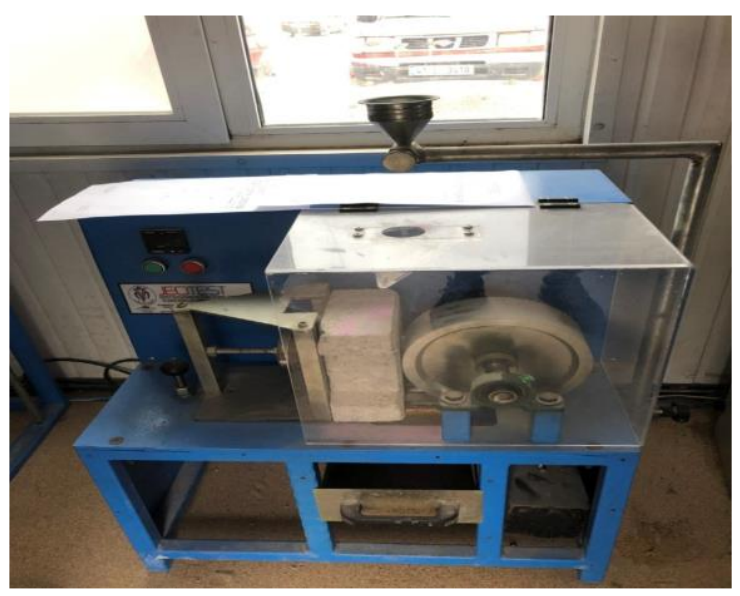

Şekil 7. Aşınma direnci deney düzeneği

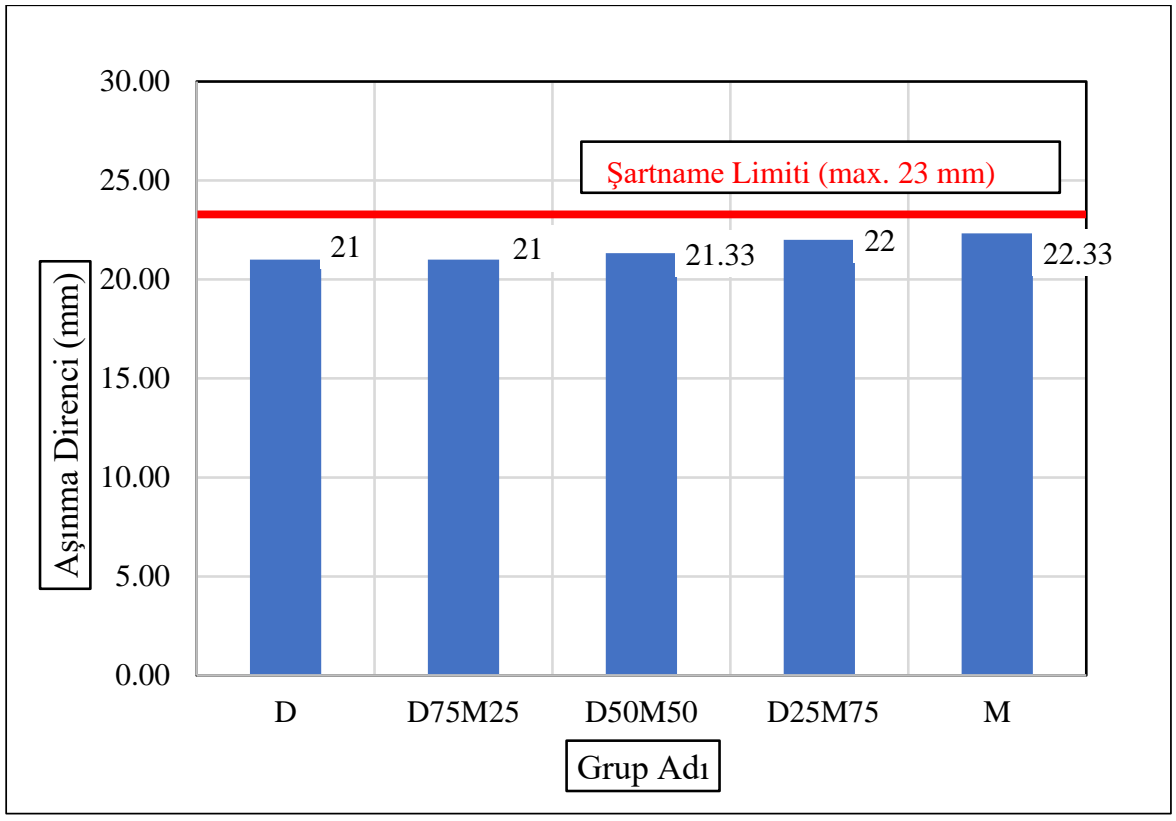

Şekil 8. Aşınma direnci deney sonuçları 


\subsection{Beton parke taşlarının yarmada çekme dayanımı deney sonuçları}

Yarmada çekme dayanımı deneyine tabi tutulacak numuneler 1 gün boyunca $20 \pm 5{ }^{\circ} \mathrm{C}$ sıcaklıktaki suda bekletilerek sudan çıktı̆̆ında temiz bir bez ile kurulanıp deneye hazır hale getirilir. Numunelerin en uzun yarma kesiti boyunca Şekil 9'da gösterilen deney düzeneğinde yükleme başlıklarına değmesi sağlanır. Daha sonra, yerleştirme parçaları ile yükleme başlığı ekseni numunelerin yarılma kesitiyle aynı çizgi üzerinde olacak şekilde cihaza konur. Kırılma yükü $(P)$, yükleme hızı $0.05 \pm 0.01 \mathrm{~N}$ olacak şekilde kesintisiz ve düzgün bir biçimde artırılarak uygulanır. Kırılmanın meydana geldiği yük, kırılma yükü olarak kaydedilir. Şekil 10'da yarmada çekme deneyi sonrası kırılan numunelere ait görüntü verilmiştir. Şekil 11'de görüldüğü gibi katkısız numuneleri ile $\% 25$ ve $\% 50$ oranında ince mermer agregası içeren numune gruplarının mukavemet değeri standartta belirtilen sınırlar içerisinde olup, $\% 75$ ve $\% 100$ atık mermer ince agregası içeren numunelerin yarmada çekme dayanım sonuçları standartta verilen değeri sağlayamamıştır.

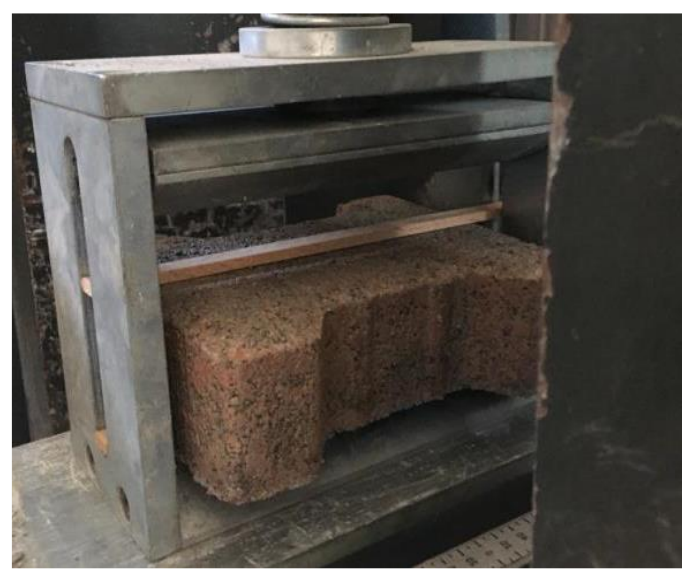

Şekil 9. Yarmada çekme deneyi

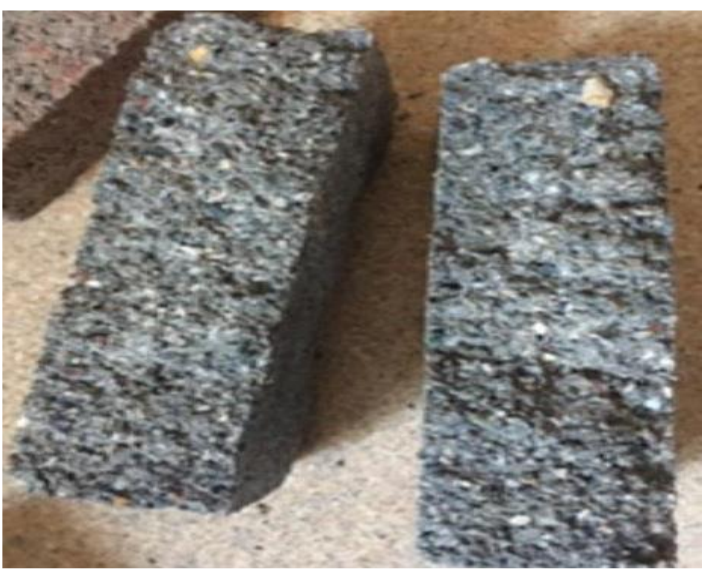

Şekil 10. Yarmada çekme deneyi sonucu kırılmış numune

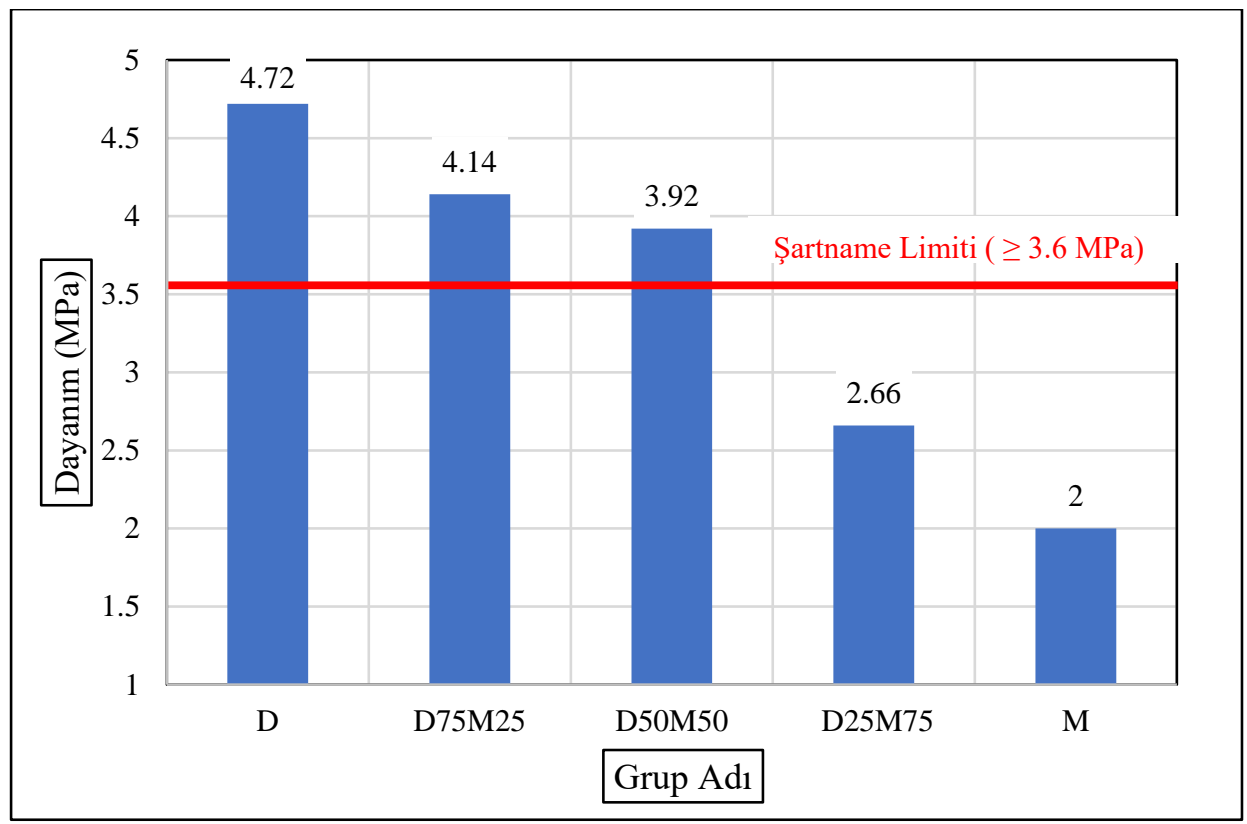

Şekil 11. Yarmada çekme dayanımı deney sonuçları

\subsection{Beton parke taşlarının su emme oranı tayini deney sonuçları}

Deneye tabi tutulan numuneler, üzerindeki gevşek malzemelerden temizlenip $20^{\circ} \mathrm{C}$ sıcaklıktaki suya konularak sabit kütleye (M1) ulaşıncaya kadar 72 saat süre ile su dolu havuzda bekletilir. 72.saatten sonra 1 gün ara ile oda sıcaklığındaki numuneye yapılan 2 tartım arası kütle farkı \%0.1'den az olduğunda sabit doygun kütleye ulaşıldığı kabul edilir. Tartım öncesinde numune temiz bir bez ile kurulanır. Tartılan numune $105^{\circ} \mathrm{C}$ sıcaklıkta sabit kuru kütleye (M2) ulaşıncaya kadar 72 saat kurutulur ve 1 gün aralıklarla yapılan 2 tartım arası kütle farkı $\% 0.1$ 'den az olunca sabit kütleye ulaştığı kabul edilir. Deney sonucunda numunelerin su emme oranı (Wa), aşağıdaki bağıntı ile kütlece \% cinsinden bulunur. Şekil 12'de su havuzunda bekletilen numuneler gösterilmiştir.

$\mathrm{Wa}=100 \mathrm{x}(\mathrm{M} 1-\mathrm{M} 2) / \mathrm{M} 2$ 


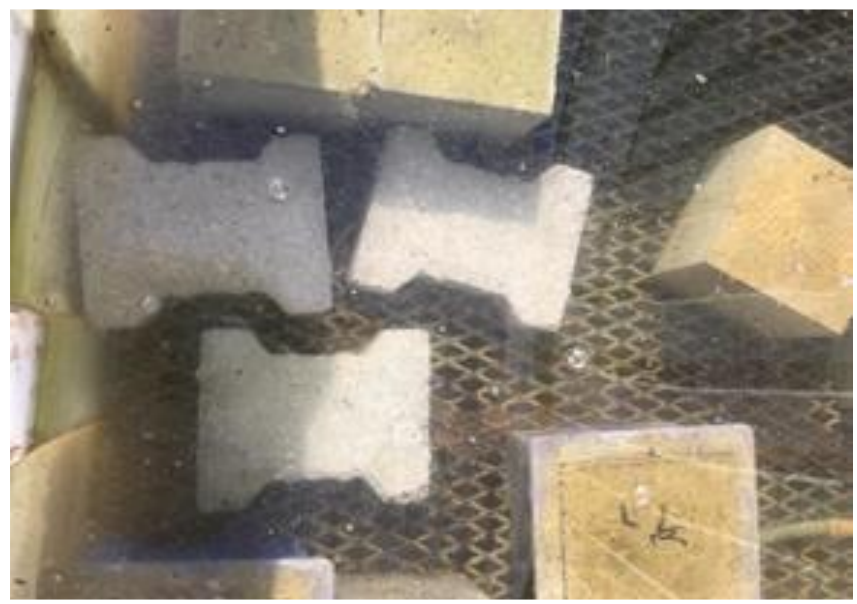

Şekil 12. $20^{\circ} \mathrm{C}$ sicaklıktaki su havuzunda bekletilen numuneler

Şekil 13’te gösterildiği gibi tüm numune gruplarının su emme değeri standartta belirtilen sınır değeri $(\leq \% 6)$ aşmamıştır.



Şekil 13. Su emme deneyi sonuçları

\subsection{Beton parke taşlarının donma-çözünme direnci tayini deney sonuçları}

Donma-çözünme deneyi yapılırken ilk olarak, deneye tabi tutulacak numuneler $91 \mathrm{~mm}$ ' lik küp biçiminde olacak şekilde elmas kesici yardımıyla kesilir. Numuneler 28 gün boyunca, kütlece $\% 97$ su ve $\% 3 \mathrm{NaCl}$ içeren çözeltiyle kaplanarak, $20^{\circ} \mathrm{C}$ sıcaklıkta, $\% 65$ bağıl nemde ve buharlaşmanın $200 \mathrm{gr} / \mathrm{m}^{2}$ olduğu iklim kabininde 7 gün bekletilir. Deneyin uygulanacağı yüzey dışındaki tüm yüzeyler plastik tabakayla kaplanır. Numune yüzeyine $20^{\circ} \mathrm{C}$ sıcaklıkta ve $5 \mathrm{~mm}$ derinlikte 72 saat boyunca su doldurularak yüzey ve plastik tabaka arasındaki yalıtımın uygunluğu gözlemlenir. Numunelerin üzerindeki su, $\% 3 \mathrm{NaCl}$ çözeltisiyle değiştirilerek $30 \mathrm{dk}$ sonra donma kabinine yerleştirilir. 28 gün donma-çözünme çevrimine maruz kalan numunelerin deney sonucunda yüzeyinde oluşan pullanma ile kalkan malzeme, su püskürtülerek kap içerisine doğru yıkanıp fırçalanarak toplanır. Toplanan malzeme süzgeç kağıdına dökülüp $\mathrm{NaCl}$ çözeltisinden arındırılarak 1 lt suyla yıkanıp 24 saat süreyle $105^{\circ} \mathrm{C}$ sıcaklıkta kurutulur. Kütle kaybı belirlenir. Şekil 14 'te gösterildiği gibi numuneler üzerinde yapılan donma-çözünme direnci deney sonuçlarına göre; tüm numune gruplarının şartnamede belirtilen sınır değeri $\left(\leq 1 \mathrm{~kg} / \mathrm{m}^{2}\right)$ aşmadığı görülmektedir. Katkısız numunesi ile kıyas yapıldığında, numunelerde mermer ince agregası oranı arttıkça donma-çözünme deneyi sonundaki kütle kaybının da arttığı görülmüştür. Ancak sınır değer aşılmadığından, deneye tabi tutulan tüm beton parke taşı numune gruplarının kullanılabilir olduğu görülmüştür. 


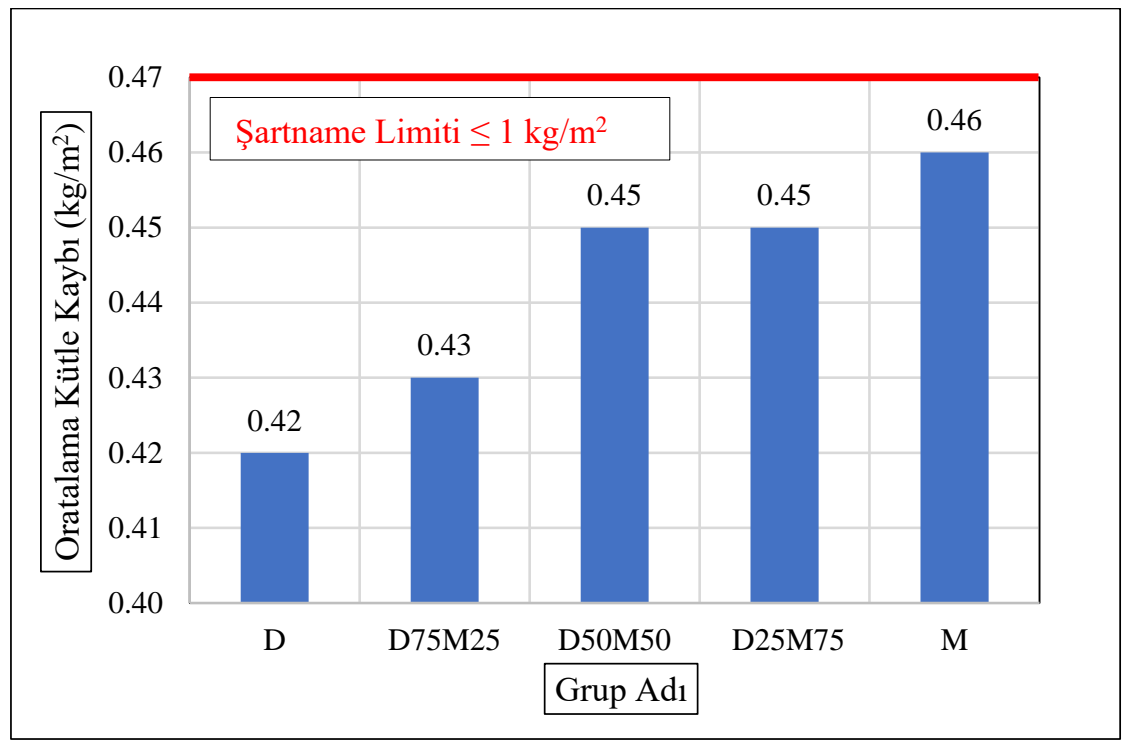

Şekil 14. Donma-çözünme direnci sonuçları

\section{Sonuçlar}

Elde edilen veriler atık mermer ince agregasının değişim oranına göre incelenmiş olup ilgili standarda göre (TS 2824 EN 1338) değerlendirme yapılmıştır.

İnce agregada doğal agrega yerine atık mermer kullanılarak hazırlanan numunelerde katkısız numunesine göre;

$\checkmark$ Boyut ve görünüş bakımından bir farklılık görülmemiştir.

$\checkmark$ Aşınma deneyi yapıldığında, numunelerin benzer aşınma direncine sahip olduğu görülmüştür.

$\checkmark$ Yarmada çekme deneyine tabi tutulan numunelerde, ince agregaya \%25 ve \%50 oranında atık mermer ikame edilmesi durumunda şartnamede belirtilen minimum dayanım değeri sağlanırken, ince agrega olarak $\% 75$ ve $\% 100$ oranında atık mermer kullanılarak hazırlanan numunelerin standartta belirtilen minimum dayanım değerini sağlamadığı görülmüştür.

$\checkmark$ Su emme oranı deney sonuçlarına göre tüm numune grupları maksimum su emme oranı (\%6) değerini aşmamıştır.

$\checkmark$ Donma-çözünme deneyi sonuçlarına göre katkısız grubu ile atık mermer içeren numune grupları benzer sonuçlar göstermiş ve şartname limit değerlerini sağlamıştır.

Numunelere uygulanan su emme deneyine göre, elde edilen beton parke taşları 2. sınıf olarak tanımlanabilmektedir. Aşınma dayanımı değerlerine göre 2. ve 3. sınıf parke grubuna dahil edilirken, donma-çözünme dayanımı bakımından 3.Sınıf parke olarak tanımlanmaktadır.

Deney sonuçları incelendiğinde beton parke taşlarında ince agrega olarak \%50 oranına kadar atık mermer agregası kullanılmasının uygun olduğu sonucuna varılmışır. Böylece atık mermerler kullanılarak istenilen mekanik ve fiziksel özelliklere sahip beton parke bloklarının elde edilebileceği görülmüsşür. Bu sayede depolanması ve taşınması problem teşkil eden atık mermerler değerlendirilerek hem çevreye verilen tahribat azaltılacak hem de alternatif bir agrega kaynağı sağlanmış olunacaktır.

İleride yapılacak olan çalışmalarda beton parke taşı üretilirken beton santralinden alınacak betona, katkı malzemeleri ilave edilerek $\mathrm{Su} /$ Çimento oranının düşürülmesi önerilmektedir. Böylece mekanik özelliklerin daha da artırılabileceği düşünülmektedir. Ayrıca mermer agregasının karışımlarda farklı oranlarda ve farklı agrega grupları içerisinde kullanılabileceği önerilmektedir.

\section{Referanslar}

Anitha Selvasofia S. D., Dinesh A.\&Sarath Babu V. (2021).Investigation of waste marble powder in the development of sustainable concrete. Materialstoday: proceedings, 44 (6), 4223-4226. doi.org/10.1016/j.matpr.2020.10.536

Baradan, B., Türkel, S., Yazıcı, H., Ün, H., Yiğiter, H., Felekoğlu, B., Tosun Felekoğlu , K., Aydın, S., Yardımcı, M. Y., Topal, A. \& Öztürk, A. U., 2015, Beton, İzmir, Birleşik Matbaacılık.

Behera M., Bhattacharyya S.K., Minocha A. K., Deoliya R., \&Maiti S. (2014). Recycled aggregate from C\&D waste \& its use in concrete - A break through towards sustainability in construction sector: A review. Construction and building materials, 68, 501-516. doi.org/10.1016/j.conbuildmat.2014.07.003 
Binici, H., (2007). Effect of crushed ceramic and basaltic pumice as fine aggregates on concrete mortars properties. Construction and building materials, 21 (6), 1191-1197. doi.org/10.1016/j.conbuildmat.2006.06.002

Coppola, L., Buoso, A., Coffetti, D., Kara, P. \& Lorenzi, S. (2016). Electric arc furnace granulated slag for sustainable concrete. Construction and building materials, 123 (2016), 115-119. doi.org/10.1016/j.conbuildmat.2016.06.142

Demir, İ. (2009). Investigation of mechanical properties of concrete produced with waste granites aggregates. Scientific Research and Essay 4 (4), 267-274.

Djamaluddin, A. R., Caronge, M. A., Tjaronge, M. W., Lando, A. T. \&Irmawaty, R. (2020).Evaluation of sustainable concrete paving blocks incorporating processed waste tea ash. Case Studies in Construction Materials, 12 (2020), doi.org/10.1016/j.cscm.2019.e00325

Durmuş, G \& Şimşek, O. (2008). Uçucu küllerin beton kilitli parke taşı üretiminde kullanımının araştırılması. TUBAV Bilim Dergisi, $1(1), 1-6$.

Filiz, M., Özel, C., Soykan, O. \& Ekiz, Y. (2010). Atık mermer tozunun parke taşlarında kullanılması. Yapı Teknolojileri Elektronik Dergisi, 6(2) 57-72.

Jankovic, K., Nikolic, D. \&Bojovic, D. (2012). Concrete paving block sand flags made with crushed brick as aggregate. Construction and building materials, 28(1), 659-663. doi.org/10.1016/j.conbuildmat.2011.10.036

Karayolu Teknik Şartnamesi (Yol Altyapısı, Sanat Yapıları, Köprü ve Tüneller, Üstyapı ve Çeşitli İşler), (2013). Karayolları Genel Müdürlüğü, Ankara.

Kaya, T. \& Karakurt, C. (2016). Uygulamadaki Beton Parke Taşlarının Mühendislik Özelliklerinin İncelenmesi. Düzce Üniversitesi Bilim ve Teknoloji Dergisi, 4(2016), 469-474.

Khandve, P. V. \& Rathi, A. S., (2015). Concrete paving block using marble stone industry waste. International Journal of Research in Engineering, Science and Technologies (IJRESTs), 1 (8), 86-91.

Kim, H. K. \& Lee, H.K. (2011). Use of power plant bottom ash as fine and coarse aggregates in high-strength concrete. Construction and building materials, 25(2011), 1115-1122. doi.org/10.1016/j.conbuildmat.2010.06.065

Ling, T-C, (2012). Effects of compaction method and rubber content on the properties of concrete paving blocks. Construction and building materials, 28(1), 164-175. doi.org/10.1016/j.conbuildmat.2011.08.069

Miraldo, S., Lopes, S., Pacheco-Torgal, F. \& Lopes, A. (2021). Advantages and short comings of the utilization of recycled wastes as aggregates in structural concretes. Construction and building materials, 298 (2021), 123729. doi.org/10.1016/j.conbuildmat.2021.123729

Oikonomou N. D. (2005). Recycled concrete aggregates. Cement and Concrete Composites, 27 (2), 315-318. doi.org/10.1016/j.cemconcomp.2004.02.020

Öztürk, M., (2018). Mermer Kesiminden Kaynaklanan Çevre Kirliliği ve Önlemleri. Çevre ve Şehircilik Bakanlığı, http://www.cevresehirkutuphanesi.com/assets/files/slider_pdf/5mgT7FNMcjwz.pdf.

Patra, R. K. \&Mukharjee, B. B. (2017). Influence of incorporation of granulated blast furnace slag as replacement of fine aggregate on properties of concrete. Journal of cleaner production. 165 (2017), 468-476. doi.org/10.1016/j.jclepro.2017.07.125

Saloni, Parveen, Lim, Y. Y., Pham T. M., , Jatin\& Kumar J. (2021). Sustainable alkali activated concrete with fly ash and waste marble aggregates: Strength and Durability studies. Construction and building materials, 283, 122795, doi.org/10.1016/j.conbuildmat.2021.122795

Silva, D., Gameiro, F., de Brito, J., (2013). Mechanical properties of structural concrete containing fine aggregates from waste generated by the marble quarrying industry. J. Mater. Civ. Eng. (ASCE) 26 (6), 04014008. https://doi.org/10.1061/(ASCE)MT.1943$\underline{5533.0000948}$

TS 2824 EN 1338, (2006). Concrete paving blocks - Requirements and test methods. Turkish Standard Institution, Ankara, 2012. 
TS EN 197-1. (2012). Cement-Part 1: compositions and conformity criteria for common cements. Turkish Standard Institution, Ankara, 2012.

TS 802, (2016). Beton karışım tasarımı hesap esasları. Ankara, 2016.

Yüksel, İ., Özkan, Ö. \& Bilir, T. (2007). Yüksek Fırın Cürufu İkameli Parke ve Bordür Üretimi. Pamukkale Üniversitesi Mühendislik Bilimleri Dergisi, 13(2), 289-296. 